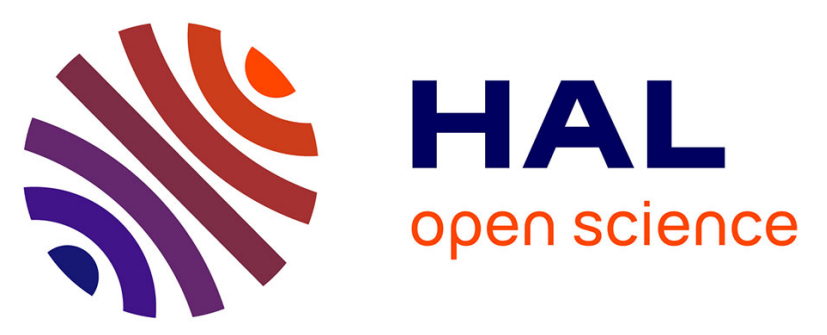

\title{
CdSxSe1-x nanocrystals grown from solid solution in silicate glass. Structural and interfacial aspects. High resolution transmission electron microscopy and optical absorption spectroscopy
}

\author{
M. Gandais, M. Allais, Yunlin Jacques Zheng, Maria Chamarro
}

\section{To cite this version:}

M. Gandais, M. Allais, Yunlin Jacques Zheng, Maria Chamarro. CdSxSe1-x nanocrystals grown from solid solution in silicate glass. Structural and interfacial aspects. High resolution transmission electron microscopy and optical absorption spectroscopy. Journal de Physique IV Proceedings, 1994, 04 (C3), pp.C3-47-C3-56. 10.1051/jp4:1994306 . jpa-00252503

\section{HAL Id: jpa-00252503 https://hal.science/jpa-00252503}

Submitted on 1 Jan 1994

HAL is a multi-disciplinary open access archive for the deposit and dissemination of scientific research documents, whether they are published or not. The documents may come from teaching and research institutions in France or abroad, or from public or private research centers.
L'archive ouverte pluridisciplinaire HAL, est destinée au dépôt et à la diffusion de documents scientifiques de niveau recherche, publiés ou non, émanant des établissements d'enseignement et de recherche français ou étrangers, des laboratoires publics ou privés. 


\title{
$\mathrm{CdS}_{x} \mathrm{Se}_{1-x}$ nanocrystals grown from solid solution in silicate glass. Structural and interfacial aspects. High resolution transmission electron microscopy and optical absorption spectroscopy
}

\author{
M. GANDAIS, M. ALLAIS, Y. ZHENG and M. CHAMARRO*
}

Laboratoire de Minéralogie-Cristallographie de Paris (LMCP), associé au CNRS, Universités Paris VI et Paris VII, 4 Place Jussieu, 75252 Paris cedex 05, France

* Groupe de Physique des Solides (GPS), associé au CNRS, Universités Paris VI et Paris VII, 4 Place Jussieu, 75252 Paris cedex 05, France

\begin{abstract}
CdS}_{0.4} \mathrm{Se}_{0.6}$ nanocrystals have been formed through nucleation and growth processes during heat treatments at different temperatures $\left(\mathrm{T}=600,675\right.$ and $\left.700^{\circ} \mathrm{C}\right)$ and annealing times $(\mathrm{t}=1$ hour to 8 days). A regime of nucleation and growth seems to occur at $\mathrm{T}=600^{\circ} \mathrm{C}$. The growth process is dominant at $\mathrm{T}=675$ and $700^{\circ} \mathrm{C}$. The average size of the semiconductor particles ranges between 2 and $15 \mathrm{~nm}$ according to the temperature and annealing time. Structural and interfacial aspects of the particles at early stages of the growth are presented here.
\end{abstract}

\section{Introduction}

In the recent years, semiconductor nanocrystals in dielectric matrix have been in the center of extensive investigations in the field of optics. When nanocrystals have sizes comparable to the Bohr radius of the exciton in the bulk semiconductor, the resulting three-dimensional confinement strongly modifies their optical properties 1,2 . The influence of quantum confinement on nonlinear optical properties has been also largely studied for technological purposes. These properties are promising for future developments of information processing and transmission of signal 3,4. In this framework, a number of researches have been dedicated to the fabrication of semiconductor nanocrystals in different types of dielectric matrices (either solids : glasses, sol-gels, ionic crystals, zeolithes, polymers,... or liquids). Although restricted to a few semiconductor species, the growth of particles by diffusive transformation from dilute solid solution in silicate glass has received much attention. On the one hand, the mechanism may be modelized on the basis of concepts previously developed in physical metallurgy; on the other hand, devices were available for the experiments in glass manufactures. The experimental process includes several stages. At first low amounts of semiconductor components are incorporated and dissolved in molten silicate. The liquid solution is then frozen into a solid one. The nucleation and growth of semiconductor particles is finally activated through heat treatments where the particles size is controlled by the couple of parameters : temperature $T$ and annealing time $t$. In parallel to elaboration processes, characterization methods have been developed for improving our knowledge on the structural aspects of materials at nanometer scale : central scattering of either X rays or neutrons, low frequency infrared Raman scattering, transmission electron microscopy in conventional and high resolution mode etc...

The present work deals with $\mathrm{CdS} \mathrm{S}_{\mathrm{X}} \mathrm{Se}_{1-\mathrm{x}}$ nanocrystals formed by nucleation and growth in silicate glass matrix. Two complementary methods have been combined in order to investigate structural aspects 
of the particles at early stages of the growth: high resolution transmission electron microscopy (HRTEM) and optical absorption spectroscopy (OAS).

HRTEM is able to give fine informations on nanocrystals embedded in glass, even when they are in small concentration : crystal structure, shape, interface, size and size distribution.

Confinement effect has been observed in optical absorption spectra as a large blue shift of the absorption edge and the appearance of structure related to optical transitions between discrete energy levels 5 . When a simple model based on the effective mass approximation is used, it is possible to obtain information about the average size of nanocrystals from optical absorption spectra. Further, when the oscillator strength of the involved transitions is calculated as a function of size, information about the concentration of nanocrystals in the matrix may be obtained.

\section{Material}

The material studied here is a Schott glass having the composition of commercial filters RG 630, that is about $\mathrm{SiO}_{2}, 53.2$ wt\%; $\mathrm{K}_{2} \mathrm{O}, 21.4$ wt\%; $\mathrm{ZnO}, 20.3$ wt\%; $\mathrm{B}_{2} \mathrm{O}_{3}, 3.5$ wt\%; $\mathrm{NaO}_{2}, 0.4$ wt\%; $\mathrm{CdO}, 0.6$ $\mathrm{wt} \% ; \mathrm{SeO}_{2} 0.4 \mathrm{wt} \% ; \mathrm{SO}_{3}, 0.2 \mathrm{wt} \%$. The melting and quenching operations were performed at the Schott Glaswerke Center, by using the technology of commercial filters. The glass obtained after quenching was slightly yellow. The heat treatments were performed in our laboratory. Different temperatures and times were considered $\left(T=600,675\right.$ and $700^{\circ} \mathrm{C}, t$ increasing from 1 hour to 8 days at each temperature). During heat treatments, the formation of nanocrystals gives rise to optical absorption and the glass is progressively coloured. The samples heated at $600^{\circ} \mathrm{C}$ changed from yellow to orange red as the heating time increased from 4 hours to 8 days. The samples heated at higher temperatures changed from orange red to deep red as the heating time increased. The particles composition could be measured by X-rays diffraction when their average size was large enough ( $8 \mathrm{~nm}$ and above). The composition $\mathrm{CdS} 0.4 \mathrm{Se} 0.6$ has been found ${ }^{6}$.

\section{High Resolution Transmission Electron Microscopy}

\subsection{Experimental process}

HRTEM observations were made using a TOPCON EM 002B electron microscope working at $200 \mathrm{kV}$ with lattice resolution $\mathrm{r}=0.18 \mathrm{~nm}$. The glass matrix has relatively high scattering power due to the large amount of heavy oxydes, namely $\mathrm{ZnO}$ and $\mathrm{K}_{2} \mathrm{O}$; moreover, it shows contrast fluctuations at the scale of several nanometers indicating compositional fluctuations within the amorphous network. The nanocrystal images taken into consideration here are lattice patterns (phase contrast) that occur generally within dark areas (amplitude contrast). They contain an important background noise caused by the surrounding glass which has been reduced by filtering the spatial frequencies through Fourier transformation 7,8 . The main frequencies of the crystal were selected with an annular filter and the low frequencies, associated to amplitude contrast, were selected with a central filter.

In each sample, 40 - 60 crystallites were examined. The lattice and habit of each crystal were analysed and the linear dimension $s_{i}$ was measured (with the accuracy of about one lattice spacing, i.e. $0.33-0.37 \mathrm{~nm}$ and a visibility threshold of about $3 \mathrm{~nm}$ ). The average size $s$ and the standard deviation $\sigma$ were calculated. Details concerning the definition of the size parameters and the accuracy of the 
measurements are given elsewhere ${ }^{9}$.

\subsection{Results}

\section{Crystal structure :}

As early as they are visible $(s \approx 3-4 \mathrm{~nm}$ ) the semiconductor particles are crystallized in the hexagonal structure of wurtzite type as the bulk material. Figure 1 shows typical lattice images presenting the symmetries of the wurtzite structure (P63mc). The projection along $a$-axis is particularly interesting since it displays effects of the $6_{3}$ symmetry axis in dynamical conditions of diffraction. The odd reflexions along $c^{*}$ axis, forbidden by $6_{3}$ symmetry, are effectively at extinction when $a$-axis is strictly parallel to the electron beam. In this case, the lattice pattern displays the periodicity $c / 2$ (figure $1 \mathrm{a}$ ). But the extinction laws are transgressed by double diffraction process when the zone axis is misaligned. In this case, the periodicity $c$ appears (figure $1 b$ ). The high sensitivity of the image to misalignement has been shown through image simulation 10 : working at $100 \mathrm{kV}$, the $c$ periodicity is evident in the image of CdSe crystals at the relatively small thickness of $4.8 \mathrm{~nm}$, when a tilt angle of $2.0 \mathrm{mrad}$ is introduced. Therefore, close to this orientation, a large number of patterns show $c$ periodicity.

Crystal habit:

In the early stages of growth, the particles are close in shape to spheres, although low index faces tend to develop (figure $1 \mathrm{a}, \mathrm{b}, \mathrm{d}$ ). In more advanced stages the densiest faces spread out, giving rise to habit close to the hexagonal prism. The six-fold symmetry of the prism is clearly seen in view along $c$-axis (figure 1e). The lack of centre of symmetry, in relation with the polarity of the atomic arrangement, is also displayed in views along $a$-axis by the dissymmetry of the opposite basal faces (figure $1 \mathrm{a}, \mathrm{c}$ ). On one side of the $c$-axis the basal face is flat and well-developed whereas the opposite face generally contains steps and keeps a curved aspect. The transformation from sphere to prism occurs at a size limit $s_{l}$ ranging between 7 to $10 \mathrm{~nm}$ according to the heating temperature. Above this size, the prisms progressively grow longer in direction of $c$-axis (figure $1 \mathrm{c}$ ) 11 .

The ideal symmetry described above is not always realized. Crystals showing unequal development of prismatic faces are sometimes observed. Their dissymetric growth is likely in relation with compositional heterogeneities of the matrix (figure 1f).

Crystal quality, crystal-glass interface:

Most of the semiconductor particles are perfectly crystallized, at least in the core. The lattice defects exceptionally observed consist in stacking faults in the hexagonal sequence ${ }^{8}$. These defects do not modify the bonds between first neighbours and probably have few influence on the optical properties.

Whereas the crystal core poses no problem, the crystal-glass interface seems to be more complex. At first, the lattice image systematically displays an abrupt drop of contrast at the crystal border, over a width of about $1-2$ unit cells and the intensity peaks are sometimes displaced. These modifications occur not only in the case of spherical crystals, but also in the case of apparently flat interfaces seen endon, such as basal and prismatic faces (figure $1 \mathrm{a}$ and e respectively). The low contrast at the crystal border may be the effect of either small thickness or misordering of interfacial layers and suggests two models of crystal-glass interface. The simplest model consists in crystal of unaltered structure up to the interface. In this model, the low contrast of the lattice pattern could be explained by the presence of 

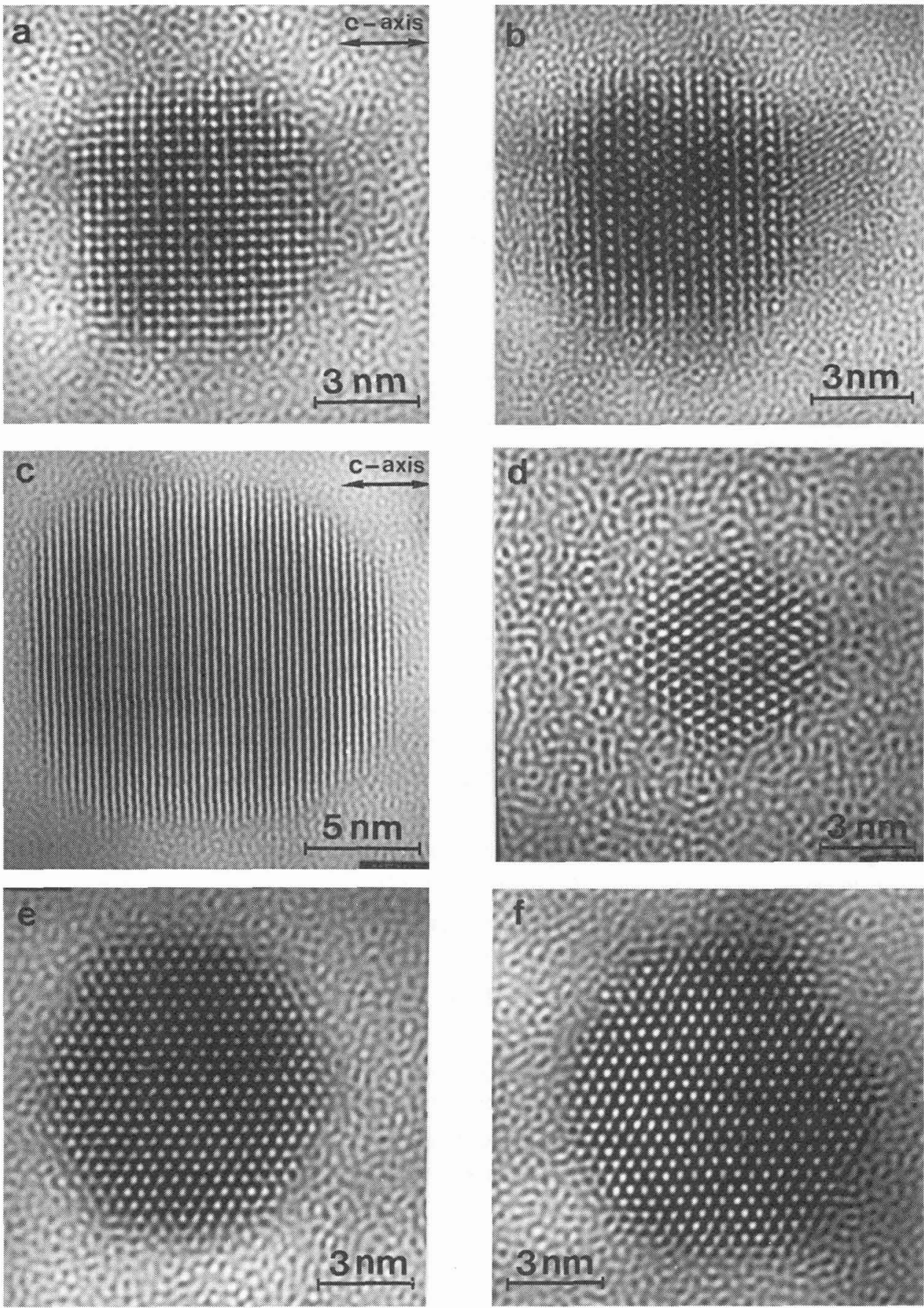

Figure 1 . (a), (b) : the same crystal viewed along a direction close to $a$-axis, $675^{\circ} \mathrm{C}-4 \mathrm{D}$; (c) : (0002) lattice fringes, $700^{\circ} \mathrm{C}-4 \mathrm{D}$; (d) - (f) : views along c-axis; (d): $675^{\circ} \mathrm{C}-2 \mathrm{D}$; (e), (f) : $675^{\circ} \mathrm{C}-4 \mathrm{D}$. 
terraces of small dimensions at the interface. However, the simplifying concept of unaltered crystal structure up to the interface is questionable, in the light of the present knowledge. In the last decade, the concept of particular interfacial structure has been introduced through modelizations of atomic arrangements at the crystal-melt interface of monoatomic close packed crystals ${ }^{12}$. The modelizations have shown the existence of progressively misordered layers between the perfect crystal phase and the perfectly disordered liquid phase. Although the modelization concerns crystal and liquid of simple composition, the model of interfacial layers appears to be more general since it emphasizes the need of transitional layers for accommodating incompatible structures. Therefore, the model of progressively disordered layers seems to be a better approach of the crystal-glass interface studied here.

A second aspect often observed is the extension of the amplitude contrast outside the lattice image over several unit cells. This feature suggests the existence of small part of crystal in misorientation at the interface. In exceptional conditions of orientation, misoriented crystal is clearly displayed by the presence of lattice pattern in prolongation of the main lattice (figure $1 \mathrm{~b}$ ). The nature of the misoriented crystal has not been elucidated and different hypothesis may be considered. (i) The misoriented part is not of the same composition as the main crystal. Nanocrystals of other species have been observed; some of them have been assumed to be $\mathrm{ZnO}$, from lattice pattern identification 13 . They are already present in the quenched glass and they do not grow anymore during heat treatments : their size remains at about $4 \mathrm{~nm}$. These crystals could have been centers for heterogeneous nucleation of the semiconductor particles. (ii) The small misoriented crystal is part of the semiconductor particle, nucleated at the surface of the main one, at the favour of defects. In this hypothesis, the misoriented part is probably unstable and recrystallizes during the growth, taking the orientation of the main crystal. In later stages, their development is not evidenced by the presence of either bicrystals or polycrystals, at least in the range of sizes considered here. Polycrystalline aggregates have been found also, but at much later stages of the growth when the sizes are larger than $20 \mathrm{~nm}$. At these stages, the conditions of growth have been probably changed, mainly in relation with increasing strains.

Crystal size :

The mean size $s$ of crystals as a function of temperature and time is presented in Figure 2, where the error bar represents the 95 percent confidence interval for the mean size. In every run, monomodal size distribution functions have been found with size dispersions approximately proportional to the mean size $(\sigma / s \approx 0.25$ ). We may notice that the size dispersion is relatively small in the range of quantum sizes: $\sigma=1.3 \mathrm{~nm}$ at $s=5 \mathrm{~nm}$.

\section{Optical absorption spectroscopy}

Optical absorption measurements were performed at room temperature with a BECKMAN acta III spectrophotometer. The different samples were polished to appropriate thickness. For example, the glass annealed at $700^{\circ} \mathrm{C}, 4$ days was polished to a thickness of $0.07 \mathrm{~mm}$ whereas the sample annealed at $600^{\circ}$ $\mathrm{C}, 8$ hours was polished to a thickness of $0.66 \mathrm{~mm}$.

Figure 3a shows the absorption spectra of samples annealed at $600^{\circ} \mathrm{C}$ for various heating times. We clearly see the appearance of a structure due to the quantum confinement effect and the red shift of the absorption edge when the heating time increases. Moreover, absorption increases when the heating 


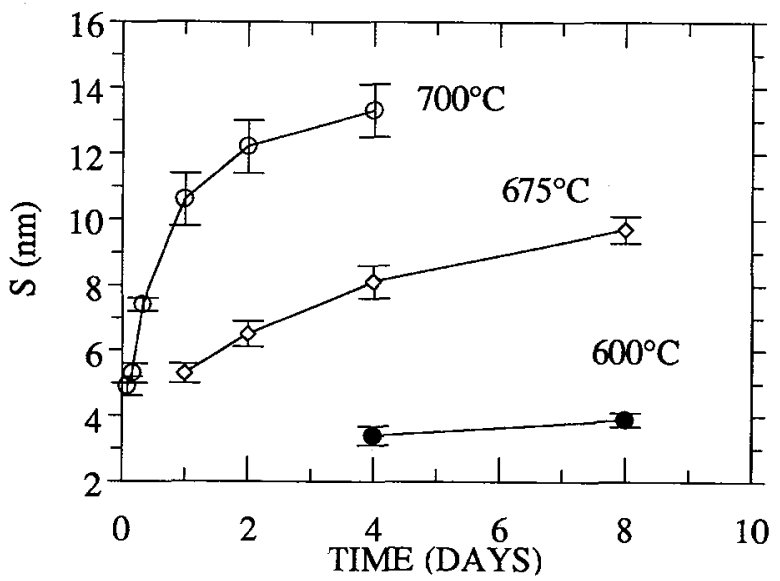

Figure 2 Average size $s$ as a function of heating time at different temperatures. Results from METHR.
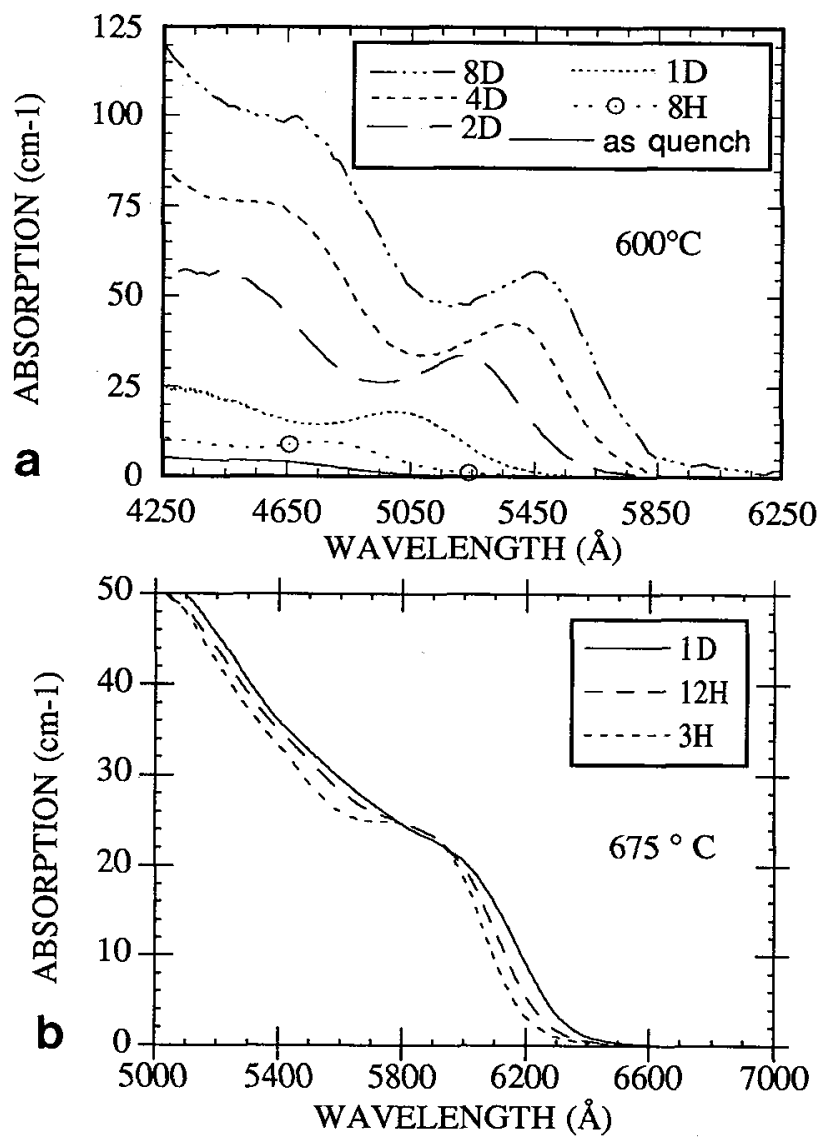

Figure 3. Optical absorption at a) at $600^{\circ} \mathrm{C}$ and b) at $675^{\circ} \mathrm{C}$ 
time increases. We can also see an absorption band on the non-annealed sample. This band could be related to the presence of either impurities or small semiconductor crystals in the glass matrix.

The absorption spectra of samples annealed at $675^{\circ} \mathrm{C}$ during 3,12 and 24 hours are given in Figure $3 \mathrm{~b}$. In this case, absorption spectra are broad and featureless and we can see that the shoulder on the low-energy side broadens and moves slightly to a longer wavelength as the heating time increases. The absorption spectrum obtained for 6 hour treatment has not been represented because there is not special changes with respect to 3 hour treatment.

In the case of treatments at $700^{\circ} \mathrm{C}$, the samples heated during 1,2 and 4 hours present similar optical spectra to those shown in Figure $3 \mathrm{~b}$. The spectra of samples heated during 1 and 2 days are identical to each other. They are still broader than the previous ones.

A simple model used to describe the optical properties of the semiconductor nanocrystals embedded in a glass matrix considers the effect of boundaries on the electron and hole wave functions of bulk crystals. The enveloped functions of electrons and holes are modified by an infinitely deep spherical potential well and electron-hole Coulomb interaction. Usually two extreme situations are considered : in the first, called strong confinement regime, the energy of electron and hole confinement is assumed to be dominant relative to the Coulomb interaction energy; in the second one, called weak confinement regime, the Coulomb interaction energy is assumed to be dominant.

The strong confinement assumption allows us to consider the electron and the hole practically uncorrelated like individual particles and results in a splitting of both valence band and conduction band in a series of discrete energy levels. The lowest energy transition occurs between the $n=1, l=0$ hole state and the $n=1, l=0$ electron state (1S-1S transition) and its energy is given by 14 :

$$
E_{1 S-1 S}=E_{g}+\frac{\hbar^{2} \pi^{2}}{2 \mu R^{2}}-\frac{1.8 e^{2}}{\varepsilon R}
$$

where $E_{g}$ is the bulk crystal band gap, $\mu$ is the reduced electron-hole mass, $R$ the radius of the semiconductor nanocrystal and $\varepsilon$ the dielectric constant of the semiconductor. The second term represents the kinetic energy of both electron and hole and the third one is their Coulomb attraction introduced in calculations as a perturbation.

On the other hand, a weak confinement assumption results in an exciton state as lowest energy state, but with energy shift due to the confinement. This regime becomes the real situation when the exciton radius $\left(a_{0}\right)$ is sufficiently small compared to the crystal radius $(R)$. Between these two extreme situations, we can also consider an intermediate confinement regime. In this case, the Coulomb interaction may not be neglected.

In practice, the weak confinement regime is accomplished when the nanocrystal radius is bigger than three times the exciton radius of the bulk material and the strong confinement regime is accomplished when the nanocrystal radius is smaller than the exciton radius 15 . The value of exciton radius is equal to 5.6 and $3.0 \mathrm{~nm}$ in CdSe and CdS respectively. By interpolation, the value of exciton radius in $\mathrm{CdS}_{0.4} \mathrm{Se}_{0.6}$ would be equal to $4.5 \mathrm{~nm}$. We can conclude that the weak confinement treatment is never appropriate for the nanocrystals considered in the present work, whereas strong confinement is a convenient treatment for sizes in the range of $1-4 \mathrm{~nm}$. 
To determine the average radius of our nanocrystals we applied the expression (1) to the first absorption maximum. The average parameters of $\mathrm{CdS}_{0.4} \mathrm{Se}_{0.6}$ crystals used are $E_{g}=1.85 \mathrm{eV} 16$, $\mu=0.144 \mathrm{~m}_{0} 17,18$ ( $\mathrm{m}_{0}$ is the free electron mass) and $\varepsilon=8.9619,20,21$. The results are summarized in Table 1. In the quenched glass $Q$, if we assume that the absorption band centered at $456 \mathrm{~nm}$ is due to the presence of small amount of semiconductor particles, we find a radius $R=1.6 \mathrm{~nm}$. The same value is found by extrapolating towards $t=0$, the radius values as a function of heating time. The agreement between these two approaches supports the assumption of the presence of semiconductor particles.

Table 1 : average diameter of crystals as a function of temperature $T$ and heating time $t . \mathrm{Q}:$ quenched glass

\begin{tabular}{|c|c|c|c|c|c|c|c|c|c|c|c|c|c|c|}
\hline \multirow{2}{*}{$\begin{array}{c}T\left({ }^{\circ} \mathrm{C}\right) \\
t \\
t\end{array}$} & \multirow[t]{2}{*}{$\mathrm{Q}$} & \multicolumn{6}{|c|}{600} & \multicolumn{4}{|c|}{675} & \multicolumn{3}{|c|}{700} \\
\hline & & $4 \mathrm{~h}$ & $8 \mathrm{~h}$ & $1 \mathrm{~d}$ & $2 \mathrm{~d}$ & $4 \mathrm{~d}$ & $8 \mathrm{~d}$ & $3 \mathrm{~h}$ & $6 \mathrm{~h}$ & $12 \mathrm{~h}$ & $1 \mathrm{~d}$ & $1 \mathrm{~h}$ & $2 \mathrm{~h}$ & $4 \mathrm{~h}$ \\
\hline $2 R(\mathrm{~nm})$ & 3.2 & 3.3 & 3.4 & 3.7 & 4.0 & 4.2 & 4.4 & 5.1 & 5.1 & 5.4 & 5.7 & 5.4 & 5.5 & 5.6 \\
\hline $\begin{array}{c}S(\mathrm{~nm}) \\
(\mathrm{HRTEM})\end{array}$ & & & & & & 3.4 & 3.9 & & & 4.6 & 5.3 & & 4.9 & 5.3 \\
\hline
\end{tabular}

\section{Discussion}

The first point of discussion concerns the interfacial energy of the cadmium sulfo-selenide phase in silicate glasses. The authors having worked on similar materials have found particles crystallized in the wurzite structure 22,23 , which is the stable phase at room temperature and we have shown that the stable phase is formed from the early stages of growth. At the opposite, the authors concerned with colloidal particles of the same species have observed the blend structure in the early stages of growth and the progressive transformation into wurzite structure during the growth 24,25 . In silicate glass it appears that the interfacial energy $\gamma$ is low and does not constitute a significant barrier to the formation of the stable phase during the nucleation stage. The activation energy of nucleation which is, for simplicity, approximated to $\gamma^{3} / \Delta \mu^{2}$ is controlled by $\Delta \mu$, the supersaturation term ${ }^{26}$. The opposite situation occurs in conditions of colloidal growth. The interfacial energy being high, the blend phase which is stable at high temperature is favoured during nucleation because it has smaller surface energy than the wurzite phase. Allotropic phases stable at higher temperature have systematically smaller surface energy than the low temperature phases. $\mathrm{Cd}(\mathrm{S}, \mathrm{Se})$ particles in glasses and in colloidal formation give one more example of the importance of the interface energy term in the nucleation process, which has been postulated by the Ostwald's rule 26 .

A second point concerns the evaluation of nanocrystals concentration in the matrix, which is important for understanding the growth mechanisms. Nanocrystals concentration cannot be easily evaluated through HRTEM but it could be done through OAS. Optical absorption is proportional to the oscillator strength of the transitions involved. In a very simple model, the oscillator strength is independent of nanocrystal size when $R<a_{0}$, whereas it is proportional to the volume of nanocrystals when $R>a_{0} 27$. In the first case $\left(R<a_{0}\right)$, optical absorption at the first maximum would be proportional to the number of average sized nanocrystals. Samples heated at $600^{\circ} \mathrm{C}$ satisfy the first condition. Their absorption spectra show an increase of optical absorption and nanocrystals average radius as the heating time increases (Figure $3 \mathrm{~b}$ and Table 1). These features would indicate a regime of nucleation and growth in the oversimplified model mentioned above. Calculations of oscillator strength as a function of size are 
in progress in order to give a meaningful interpretation of OAS measurements.

The last point of the discussion concerns the size determination. For reasons indicated above, the measurements were possible beyond $3 \mathrm{~nm}$ in HRTEM and below $6 \mathrm{~nm}$ in OAS. In the range of sizes measured by both methods (from 4 to $6 \mathrm{~nm}$ ), nanocrystals have approximately spherical shapes. Then the dimension measured by HRTEM is close to the diameter $(s=2 R)$. The values measured by HRTEM and OAS are reported in Table 1 . They are in much better agreement than the values measured by HRTEM, on the one side, and by central X-rays diffusion and low frequency inelastic Raman scattering on the other side ${ }^{9}$. Nevertheless, there is a slight and systematic discrepancy, mainly at the smallest sizes : the values provided by HRTEM are smaller than those given by OAS. It has been mentioned elsewhere that in HRTEM image, only the single crystal part of the particle has been taken into account, and its diameter may have been underestimated by a value of $1-3$ unit cells $(\approx 0.3-1 \mathrm{~nm}){ }^{9}$. Concerning OAS, we are aware of the fact that our assignment of radii is subject to possible errors due to homogeneous and inhomogeneous broadening of the transitions, possible fluctuations of crystals shapes, small variations of alloy composition and the simplicity of the used model.

If we try to explain the systematic difference of sizes measured by HRTEM and OAS only by an effect of variation of the alloy composition during the thermal treatment, we should assume for nanocrystals of $5 \mathrm{~nm}\left(T=675^{\circ} \mathrm{C}, t=3\right.$ hours) a Se content close to $70 \%$ and for nanocrystals of $4 \mathrm{~nm}$ ( $T=600^{\circ} \mathrm{C}, t=2$ days) a Se content very close to $100 \%$, instead of $60 \%$. The former case corresponds to early stage of growth and a composition differing by $10 \%$ from what is found in advanced stages may be envisaged. But the latter case corresponds to advanced stage of nucleation process and the important deviation in composition, $40 \%$, seems not to be reasonable.

Another possible source of systematic discrepancy comes from the assumptions of the used model based on the effective-mass approximation. This approach is an oversimplified description of the smallest crystals. Lippens and Lannoo 28 have used another description, through tight-binding framework, to explain quantum size effects. They have shown that in the case of CdS and $\mathrm{ZnS}$, the energy of exciton peak calculated using tight-binding approach is lower than the energy calculated using an effective-mass approach.

\section{Concluding remarks}

The combination of HRTEM and OAS appears to be promising for the study of early stages of growth of $\mathrm{CdS}_{\mathrm{X}} \mathrm{Se}_{1-\mathrm{x}}$ particles in glass matrix. Due to the strong structural contrast between crystal and glass, fine details may be observed by HRTEM, concerning the particle and the particle-glass interface. Although the latter aspect is not completely interpreted, the observations constitute a first step towards a better knowledge of the interface. Concerning OAS, it is a very sensitive method for detecting the particles at very small size and for measuring the size variations. In the range of particle diameters measured by both methods $(4-6 \mathrm{~nm}$ ), the agreement is better than $1 \mathrm{~nm}$. OAS also allows the measure of particles concentration in the matrix, if there is a fine model for evaluating the oscillator strength of the optical transitions. Before a finer model is developed for a quantitative analysis of the measurements, a simplified model has been used here and the following trends have been displayed.

In the different heat treatments $\left(T=600,675,700^{\circ} \mathrm{C}\right)$, different processes may be distinguished. 
At $600^{\circ} \mathrm{C}$, nucleation and growth seem to occur simultaneously : as the heating time increases up to 8 days, the particles grow from 3 to $5 \mathrm{~nm}$ and, in the approximation of simplified model for the oscillator strength, the number of particles increases by a factor of $5-10$. At 675 and $700^{\circ} \mathrm{C}$, the growth process is dominant in the range of heating times considered ( $t$ increasing from 1 hour to 8 days).

In spite of complex chemical composition of the glass matrix and compositional heterogeneities at the scale of several nanometers, nanocrystals of quasi perfect quality have grown. The low energy of the crystal-glass interface has allowed the nucleation of particles in the wurtzite structure, which is the stable phase at room temperature, at the opposite of what is found for colloidal particles. In the range of sizes smaller than $8-10 \mathrm{~nm}$, the particles are nearly spherical. In more advanced stages of growth, they take prismatical shapes displaying the symmetries of the wurzite structure : six-fold symmetry of the prismatic faces, lack of centre of symmetry for the basal faces.

\section{Acknowledgment}

HRTEM was performed at the Centre d'Etudes de Chimie Metallurgique, Vitry-sur- Seine, France. We are grateful to its director J.P. Chevalier for his interest to this work. We also wish to thank Dr. B. Mutaftschief for helpulf advices and suggestions. We are indebted to Dr. Remitz from the Schott Glasswerke Center for providing the glass and for his interest.

\section{References}

[1] HENNENBERGER F., PULS J., SPIEGELBERG Ch., SHÜLZGEN A., ROSSMAN H., JUNGNICKEL V. and EKIMOV A.I., Semicond. Sci. Technol. 6 (1991) A41.

[2] FLYTZANIS C., HACHE F., KLEIN M.C., RICARD D. and ROUSSIGNOL Ph., "Nonlinear Optics in Composite Materials" in : Progress in Optics XXIX, E. Wolf edt, Elsevier Science Publishers (1991) 323.

[3] YUMOTO J., FUKUSHIMA S.and KUBODERA K., Optics Letters 12 (1987) 832.

[4] DNESPROSKI V.S., KLIMOV V.I., OKOROV D.K., VANDYSHEV YU. V., Solid State Comm. 81 (1992) 227.

[5] EKIMOV A.I., EFROS A.L. and ONUSHCHENKO A.A., Solid State Comm 56 (1985) 921.

[6] RAMOS A., LYON O., and LEVELUT C., J. Appl. Phys. (1993) submitted.

[7] ZHENG Y. and GANDAIS M., J. Electron Microscopy Technique 11 (1989) 234.

[8] ALLAIS M. and GANDAIS M., J. Appl. Crystallogr. 23 (1990) 418.

[9] CHAMPAGNON B., ANDRIANASOLO B., RAMOS A., GANDAIS M., ALLAIS M. and BENOIT J.P., J. Appl. Phys. 73 (1993) 2775.

[10] GLAISHER R.W. and SPARGO A.E.C., Ultramicroscopy 27 (1989) 117.

[11] ALLAIS M. and GANDAIS M., Philos. Mag. Lett. 65 (1992) 243.

[12] BONISSENT A. and MUTAFTSCHIEF B., in : Chemistry and Physics of Solid Surfaces, R. Vanselow and W. England edts, CRC press, Boca Raton vol 3 (1982) 163.

[13] ALLAIS M. and GANDAIS M., Mater. Sci. Eng. B 9 (1991) 429.

[14] BRUS L.E., J. Chem. Phys. 80 (1984) 4403.

[15] EKIMOV A.I., HACHE F., SCHANE-KLEIN M.C., RICARD D., FLYTZANIS C., KUDRAVTSEV I.A., YAZEVA T.V., RODINA V. and EFROS. A.L., J. Opt. Soc. Am. B 10 (1993) 100.

[16] PEDROTTI F.L. and REYNOLDS D.C., Phys. Rev. B 127 (1962) 1584.

[17] HOPFIELD J.J. and THOMAS D.G., Phys. Rev. 122 (1961) 35.

[18] WHEELER R.G. and DIMMOCK J.D., Phys. Rev. 125 (1962) 1805.

[19] VOIGT J., SPIEGELBERG F., SEMONER M., Phys. Stat. Sol. (b) 91 (1979) 189.

[20] FLOHRER J., JAHNE E., PORSH M., Phys. Stat. Sol. (b) 91 (1979) 467.

[21] VERLEUR H.W. and BARKER A.S., Phys. Rev. 155 (1967) 750.

[22] BORRELLI N.F., HALL D.W., HOLLAND H.J. and SMITH D.W., J. Appl. Phys. 61 (1987) 5399.

[23] LIU L.C., KIM M.J., RISBUD S.H. and CARPENTER R.W., Philos. Mag. B 63 (1991) 769.

[24] ROSSETTI R., ELLISON J.L., GIBSON J.M. and BRUS L.E., J. Chem. Phys. 80 (1984) 4464

[25] GACOIN T., CHAPUT F., BOILOT J.P., AUBERT P., GANDAIS M., WANG Y. and LECOMTE A., SPIE vol 1758 Sol-Gel Optics II (1992) 565.

[26] MUTAFTSCHIEF B. "Nucleation Theory", in : Handbook of Crystal Growth vol. 1 D.T.J. Hurle edt, North Holland, Amsterdam , (1993) 189 - 247.

[27]WEISBUCH C. and VINER B., in : Quantum semiconductor structures : fundamentals and applications. Academic Press (1991) 176.

[28] LIPPENS P.E. and LANNOO M., Phys. Rev. B 39 (1989) 10935. 